\title{
Laparoscopic or open appendectomy for pediatric appendicitis?
}

\begin{abstract}
Background: This study aimed to compare open appendectomy (OA) and laparoscopic appendectomy (LA) in children by analyzing the differences in outcomes between the two techniques.

Materials and methods: This was a single-institution retrospective study. Data were collected from the medical records of all children $<15$ years of age who underwent an appendectomy from 2006 through 2014. Preoperative parameters, appendicitis severity, surgery time, complications, pain treatment, and postoperative outcome including days of hospital stay were collected. LA was performed with a two- or three-port technique, and a McBurney incision was adopted for OA. Conversions were regarded as $\mathrm{OA}$.
\end{abstract}

Results: A total of 406 appendectomies were performed during the study period, $146(36 \%)$ OA (61 conversions) and 260(64\%) LA. No differences were found between the two groups regarding surgery time, operative and postoperative complications, and postoperative pain treatment. In cases of Phlegmonous appendicitis, LA was associated with a significantly shorter median hospital stay than was OA (1 and 1.8 days, respectively; $\mathrm{p}<0.01)$. Healthy and Phlegmonous appendices were more commonly treated with LA ( $\mathrm{p}<0.01$ for both); gangrenous, perforated, and abscessed appendices were more commonly treated with open surgery $(p=0.02, p<0.01$, and $\mathrm{p}<0.01$, respectively)

Conclusion: The study identified no disadvantages of LA compared with OA. Therefore, LA should be the preferred technique because it is associated with a shorter hospital stay for patients with Phlegmonous appendicitis and also allows inspection of the abdominal cavity, a major diagnostic advantage.

Keywords: appendicitis, appendectomy, children, laparoscopy, open surgery
Volume 3 Issue I - 2016

\author{
Axel Elofsson,' Eric Gemryd,' Einar \\ Arnbjörnsson, ${ }^{2}$ Martin Salö ${ }^{2}$ \\ 'Department of Pediatric Surgery, Skåne University Hospital, \\ Sweden \\ ${ }^{2}$ Department of Clinical Sciences and Pediatrics, Lund University, \\ Sweden
}

Correspondence: Einar Arnbjörnsson, Senior Consultant, Associate professor, Department of Pediatric Surgery, Skåne University Hospital, Lund, and Department of Clinical Sciences, Pediatrics, Lund University, Sweden, Tel 0046706496380 Email einar.arnbjornsson@telia.com

Received: January 15, 2016 | Published: January 28, 2016
Abbreviations: CRP, c-reactive protein; CT, computed tomography; LA, laparoscopic appendectomy; OA, open appendectomy; PAS, pediatric appendicitis score; US, ultrasound

\section{Introduction}

Appendicitis is the most common disease leading to emergency abdominal surgery in children. ${ }^{1}$ Epidemiological studies indicate that approximately $12 \%$ of males and $23 \%$ of females undergo emergency appendectomy during their lifetime, while the true lifetime risk of developing appendicitis is only $9 \%$ and $7 \%$ for men and women, respectively. ${ }^{2}$ Appendicitis is most common in patients aged 10-19years. ${ }^{2}$

The decision to perform a laparotomy and appendectomy is based on clinical findings only. Imaging can provide some support for the decision. Several clinical prediction scores can be used as diagnostic aids. One of these, the pediatric appendicitis score (PAS), was specifically developed for children. The PAS combines clinical manifestations, laboratory findings, and patient history on a ten-point scale to yield a combined score. The PAS was originally described as having a sensitivity of $100 \%$ and a specificity of $92 \%$ for identifying appendicitis. $^{3}$
The standard treatment for appendicitis remains removal of the appendix, which provides a permanent cure. This can be done with open appendectomy (OA) or laparoscopic appendectomy (LA). OA was first introduced by McBurney in 1894 and was for decades the gold-standard treatment for appendicitis. ${ }^{4-6}$ In 1983, along with advances in endoscopic surgery, LA was first described as an optional technique for removing the appendix. LA can be performed using one or more laparoscopy ports. ${ }^{7,8}$

The advantages and disadvantages of the two procedures have been the subject of discussion, and no definitive consensus exists as to which operational method should be chosen in children with appendicitis. Previous studies have shown that disadvantages of LA include increased operating time, higher incidence of intra-abdominal abscesses and, in cases of complicated appendicitis (gangrenous or perforated appendix), debatable safety. ${ }^{9} 10$ Advantages of LA include reduced postoperative pain, enhanced wound healing, and earlier discharge from the hospital than with $\mathrm{OA},{ }^{11-13}$ all leading to a faster return to normal daily activities. ${ }^{11,12}$ LA is also a better method of examining the abdominal cavity, which is of importance when the appendix is found to be healthy and other causes of the symptoms need to be found. This is an advantage especially in female patients because the internal female genitalia often cause abdominal symptoms. ${ }^{14}$ Previous studies have shown that the longer operating time for LA can result from lack of experience in the technique. This difference will decrease as surgeons receive more training in endoscopic surgery. ${ }^{15}$ 
Since the introduction of LA the use of this surgical method has increased, making it the method of first choice. ${ }^{9}$ The long transition period and the continued use of both techniques are due to the split opinion among surgeons and the lack of experience in endoscopic surgery. ${ }^{9}$ According to a 2008 national cohort study of children and adults, $33 \%$ of appendectomies began as LA and $66 \%$ began as OA. ${ }^{16}$ In 1992 , the rate of intended LA was only $4 \%$; prior to that year the procedure was performed only sporadically. ${ }^{16}$ In patients aged 0-9years, 4\% of appendectomies performed from 1992 to 2008 were laparoscopic; in those aged 10-19years, the rate was $18 \%{ }^{16} \mathrm{LA}$ was performed less commonly in children than in the population as a whole (the LA rate for the total population from 1992 to 2008 was $20 \%)^{16}$

The aim of this study was to compare OA and LA in children with regard to perioperative parameters and postoperative outcome. The intention was to provide information of value to surgeons making the decision to perform appendectomy for a child. The question is whether LA or OA leads to the better outcome when treating pediatric appendicitis.

\section{Materials and methods}

\section{Settings and children}

All children underwent surgery at the Department of Pediatric Surgery. The center is a tertiary center for pediatric surgery but also serves an area of approximately 340,000 inhabitants, providing primary surgical care for children under 15 years of age. Children are admitted day and night from primary care or pediatric emergency doctors for a pediatric surgery consult when appendicitis is suspected.

\section{Study design}

This was an institution-based retrospective study. All children under 15years of age who underwent appendectomy for clinically suspected appendicitis from 2006 through 2014 were included. Patients were identified from medical and surgical records by searching for International Classification of Diseases (ICD-10) diagnosis codes $\mathrm{K} 35.2, \mathrm{~K} 35.3, \mathrm{~K} 35.8, \mathrm{~K} 36.9$, and K37.9 and procedure codes JEA00, JEA01, and JEA10. The final diagnosis of appendicitis was based on intraoperative appearance and histopathological findings. Medical and surgical records were reviewed and patient demographics, symptoms, preoperative management, surgical characteristics, and postoperative data including complications and length of hospital stay were abstracted. The PAS was calculated for each patient.

\section{Definitions}

Laboratory tests, symptoms, results of imaging, information from the abdominal examination, and the PAS were registered at the time each family first sought care for their child. For some of the children, the operative decision was made later on at the ward. LA was performed with two or three ports. Operations converted from LA to OA were counted as OA since this was not an intention-to-treat analysis. At our institution, postoperative pain management immediately after surgery is handled by anesthesiologists; hence the postoperative pain treatment registered in the study ran from the time of transfer from the postoperative unit to the inpatient ward until the time of discharge. The clinic used an informal protocol for postoperative pain management for appendicitis. Operative complications included iatrogenic perforation of the appendix, diathermic injury, and postoperative bleeding requiring re-operation. Postoperative complications included postoperative abscess, wound infection, urinary tract infection, and late-onset intestinal obstruction due to postoperative adhesions. The length of hospital stay was calculated from the time of surgery to the time that the child left the ward.

\section{Statistical analyses}

Power calculation: The intention was to study two independent patient groups with one group having half as many patients as the other. Prior data indicate that the probability of exposure among individuals in one group is 0.2 . If the true probability of exposure among patients in the other group is 0.35 , we would need to include 231 and 116 patients, respectively, to be able to reject the null hypothesis that the exposure rates for the groups are equal with a probability (power) of 0.8 . The Type I error probability associated with this test of this null hypothesis is 0.05 . A continuity-corrected chi-squared statistic or Fisher's exact test is used to evaluate this null hypothesis. Patient data were recorded using an Excel database. All data were calculated using Statistical Package for Social Sciences (SPSS) version22. Fisher's exact test, two-tailed, was used for dichotomous variables, and Student's test or the Mann-Whitney U test was used for continuous variables with or without a standard distribution, respectively. Significance was set to a $p$ value $<0.05$.

\section{Ethical consideration}

The study was performed according to the Helsinki Declaration and approved by the Regional Ethical Review Board (reg. no2010/49). The data in this study were taken from medical records of children who had undergone appendectomy. All of the data were made unidentifiable and treated anonymously to protect information about the persons included in the study. Since this is a retrospective study, the procedures were done in a standardized manner according to the hospital's protocols, and the data were collected afterwards.

\section{Results}

A total of 406 patients were included, 232boys and 174girls. Five patients were excluded because of concomitant intestinal obstruction. The follow-up time for patients receiving OA was $42 \pm 20$ months; for those receiving LA, $41 \pm 29$ months. OA was performed in 146 children (61 conversions), and LA was performed in 260 (Figure 1). The grades of inflammation in the converted surgeries were 5 abscessed, 26 perforated, 16 gangrenous, 10 Phlegmonous, and 4 healthy appendices. Reasons for these conversions were severe appendicitis with pus in the abdominal cavity, anatomical difficulties making the laparoscopic technique unsafe, and technical difficulties with the laparoscopic equipment. Boys underwent OA more often than LA, compared with girls $(p=0.04)$. Among the patients who had laparoscopic surgery, there was no difference in conversion rate between girls and boys $(21 \%$ and $18 \%$, respectively; $\mathrm{p}=0.57$ ) (Figure 1$)$.

The mean age of the patients in the OA group was significantly lower than those in the LA group $(\mathrm{p}<0.01)$ (Table 1). The duration of symptoms was significantly longer in the OA group than in the LA group, with medians of 36 and 24 hours, respectively $(p<0.01)$. There were no differences in the presence of leukocytosis or neutrophilia or in PAS between the groups. Patients who underwent OA had a significantly higher C-reactive protein (CRP) value (Table 1).

The severity of appendicitis differed significantly between patients who underwent LA and those who underwent OA. Healthy and Phlegmonous appendices were more common in children 
undergoing $\mathrm{LA}(\mathrm{p}<0.01$ and $\mathrm{p}<0.01$, respectively), while gangrenous, perforated, and abscessed appendices more commonly received OA $(p=0.02, p<0.01$, and $p<0.01$, respectively) (Table $2 \&$ Figure 2 ). The difference in surgery time between the OA group and the LA group was not significant (Table 2).

Concerning operative complications, there was no difference between the groups regarding iatrogenic perforation or bleeding (Table 3). There was a significantly higher rate of postoperative abscess formation in children who underwent OA (7\% versus $2 \%$; $\mathrm{p}=0.03)$. The frequency of wound infection was low $(<1 \%)$ and did not differ between the two groups. When comparing postoperative pain management, no differences were found between OA and LA regarding treatment with paracetamol, morphine, or non-steroidal inflammatory drugs (Table 3). Of the patients with Phlegmonous appendicitis, those in the LA group had a significantly shorter length of hospital stay than those in the OA group. For patients with a gangrenous or perforated appendix, no difference was found (Table 3).

Table I Demographics, symptoms, blood tests, and preoperative parameters in children undergoing open or laparoscopic appendectomy

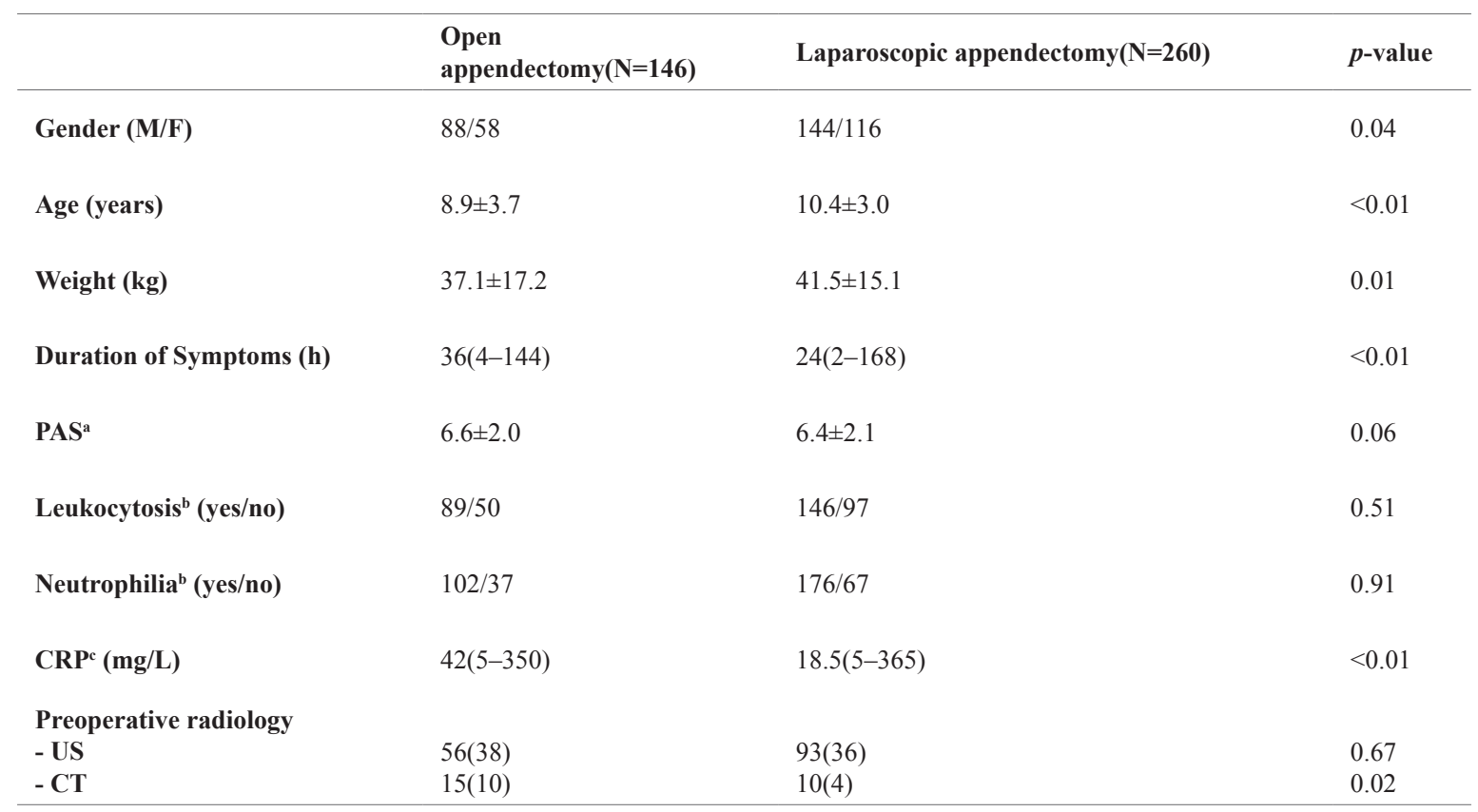

$\mathrm{N}$, numbers, with values given as absolute number (\%) of patients, as mean \pm standard deviation, or as median (minimum-maximum); M, male; F, female; PAS, pediatric appendicitis score; CRP, c-reactive protein; US, ultrasound; CT, computed tomography;

i. 6 Open Appendectomy (OA) patients excluded because of lack of data;

ii. 7 OA patients and 17 Laparoscopic Appendectomy (LA) patients excluded because of lack of data;

iii. $1 \mathrm{OA}$ patient and 1 LA patient excluded because of lack of data.

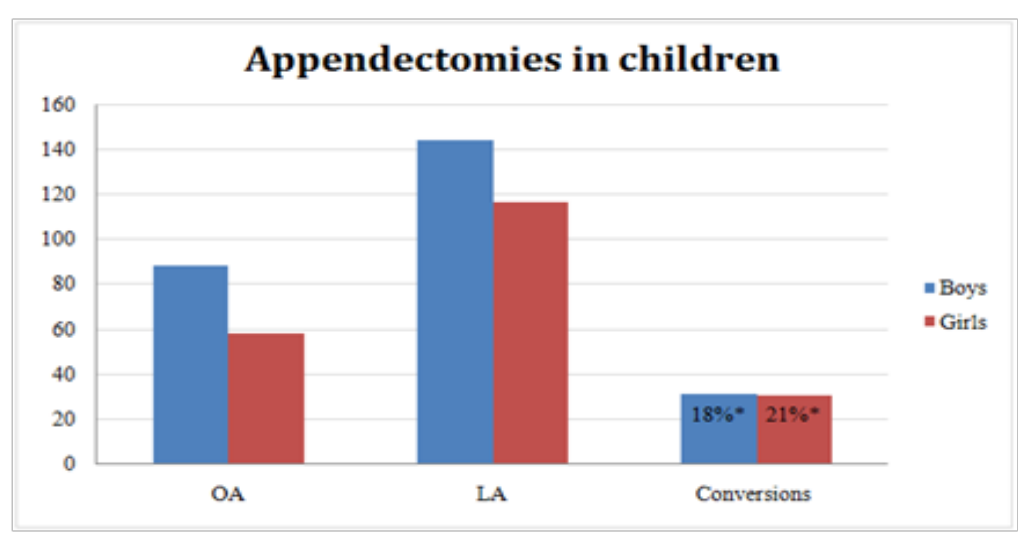

Figure 1 Distribution of appendectomies in children by gender and method.

OA, open appendectomy; LA, laparoscopic appendectomy; *= Percentage of LA converted to OA 
Table 2 Surgery time and grade of inflammation in children who underwent open or laparoscopic appendectomy

\begin{tabular}{|c|c|c|c|}
\hline & $\begin{array}{l}\text { Open } \\
\text { appendectomy }(N=146)\end{array}$ & Laparoscopic appendectomy(N=260) & $p$-value \\
\hline Surgery Time ${ }^{a}(\min )$ & $62.0 \pm 27.7$ & $59.3 \pm 22.2$ & 0.30 \\
\hline \multicolumn{4}{|l|}{ Appendicitis Grade } \\
\hline - Healthy & $8(6)$ & $39(15)$ & $<0.01$ \\
\hline - $\quad$ Phlegmonous & $49(34)$ & $168(65)$ & $<0.01$ \\
\hline - $\quad$ Gangrenous & $29(20)$ & $29(11)$ & 0.02 \\
\hline - $\quad$ Perforated & $41(28)$ & $17(7)$ & $<0.01$ \\
\hline - $\quad$ Abscess & $12(8)$ & $3(1)$ & $<0.01$ \\
\hline
\end{tabular}

$\mathrm{N}$, number, with values given as the absolute number (\%) of patients or as the mean \pm standard deviation; a: I open appendectomy patient and I laparoscopic appendectomy patient excluded because of lack of data.

Table 3 Length of hospital stay, complications, and postoperative pain management in children receiving open or laparoscopic appendectomy

\begin{tabular}{|c|c|c|c|c|c|c|c|}
\hline \multirow[b]{2}{*}{$\begin{array}{l}\text { Postoperative pain } \\
\text { treatment }\end{array}$} & \multicolumn{3}{|c|}{ Open appendectomy(N=146) } & \multicolumn{3}{|c|}{ Laparoscopic appendectomy $(\mathrm{N}=\mathbf{2 6 0})$} & \multirow[t]{2}{*}{$p$-value } \\
\hline & $\begin{array}{l}\text { Phleg. } \\
\mathrm{N}=49\end{array}$ & $\begin{array}{l}\text { Gangr. } \\
\mathrm{N}=29\end{array}$ & $\begin{array}{l}\text { Perf. } \\
\mathrm{N}=41\end{array}$ & $\begin{array}{l}\text { Phleg. } \\
\mathrm{N}=168\end{array}$ & $\begin{array}{l}\text { Gangr. } \\
\mathrm{N}=29\end{array}$ & $\begin{array}{l}\text { Perf. } \\
\mathrm{N}=17\end{array}$ & \\
\hline $\begin{array}{l}\text { Paracetamol IV } \\
(\text { doses })^{\mathrm{a}}\end{array}$ & $2(0-7)$ & $5(0-18)$ & $9(0-32)$ & $2(0-7)$ & $4(0-10)$ & $6(0-42)$ & $1 / 0.89 / 0.98$ \\
\hline $\begin{array}{l}\text { Morphine IV } \\
(\text { yes/no })^{\mathrm{b}}\end{array}$ & $17(34)$ & $16(53)$ & $31(76)$ & $37(22)$ & $15(52)$ & $9(53)$ & $0.09 / 1 / 0.12$ \\
\hline $\begin{array}{l}\text { Morphine IV } \\
(\text { doses })^{b}\end{array}$ & $1(1-4)$ & $2(1-5)$ & $2(1-16)$ & $1(1-4)$ & $2(1-6)$ & $2(1-6)$ & $0.11 / 0.90 / 0.84$ \\
\hline $\begin{array}{l}\text { Morphine IV } \\
(\mathrm{mg} / \mathrm{kg})^{\mathrm{c}}\end{array}$ & $\begin{array}{l}0.07 \\
(0.03- \\
0.26)\end{array}$ & $\begin{array}{l}0.08(0.02- \\
0.36)\end{array}$ & $\begin{array}{l}0.14(0.03- \\
0.79)\end{array}$ & $\begin{array}{l}0.07(0.03- \\
0.40)\end{array}$ & $\begin{array}{l}0.08(0.03- \\
0.35)\end{array}$ & $\begin{array}{l}0.14(0.07- \\
0.35)\end{array}$ & $0.55 / 0.72 / 0.44$ \\
\hline $\begin{array}{l}\text { NSAID } \\
\text { (yes/no) }^{\mathrm{d}}\end{array}$ & $24(48)$ & $19(66)$ & $29(71)$ & $83(50)$ & $19(66)$ & $15(88)$ & $1 / 1 / 0.20$ \\
\hline $\begin{array}{l}\text { Hospital stay (days) } \\
\text { - Phlegmonous } \\
\text { - Gangrenous } \\
\text { - Perforated } \\
\text { - Abscess }\end{array}$ & $\begin{array}{l}1.8(0.5-4) \\
4.0(1-10) \\
6(3-20) \\
9.3(5-60)\end{array}$ & & & $\begin{array}{l}1.0(0.5-13) \\
3.0(1-8) \\
5(1.5-35) \\
10(7-40)\end{array}$ & & & $\begin{array}{l}<0.01 \\
0.13 \\
0.51 \\
\mathrm{n} / \mathrm{a}\end{array}$ \\
\hline $\begin{array}{l}\text { Operative } \\
\text { complications } \\
\text { - Iatrogenic } \\
\text { perforation } \\
\text { - Bleeding } \\
\text { - Diathermic injury }\end{array}$ & $\begin{array}{l}4(3) \\
0(0) \\
X\end{array}$ & & & $\begin{array}{l}6(2) \\
1(0) \\
1(0)\end{array}$ & & & $\begin{array}{l}0.75 \\
1 \\
\mathrm{n} / \mathrm{a}\end{array}$ \\
\hline $\begin{array}{l}\text { Postoperative } \\
\text { complications } \\
\text { - Abscess } \\
\text { - Wound infection } \\
\text { - UTI } \\
\text { - Intestinal } \\
\text { obstruction }\end{array}$ & $\begin{array}{l}10(7) \\
1(0)\end{array}$ & & & $\begin{array}{l}6(2) \\
2(1)\end{array}$ & & & $\begin{array}{l}0.03 \\
1\end{array}$ \\
\hline
\end{tabular}

$\mathrm{N}$, number, with values given as the absolute number (\%) of patients or as the median (minimum-maximum); n/a, not applicable; IV, intravenous; NSAID, nonsteroidal anti-inflammatory drug; UTI, urinary tract infection.

i. 7 Open Appendectomy (OA) patients excluded because of lack of data;

ii. 9 OA patients and 3 Laparoscopic Appendectomy (LA) patients excluded because of lack of data;

iii. $8 \mathrm{OA}$ patients and $3 \mathrm{LA}$ patients excluded because of lack of data;

iv. 7 OA patients and 3 LA patients excluded because of lack of data;

v. Only 3 LA patients. 


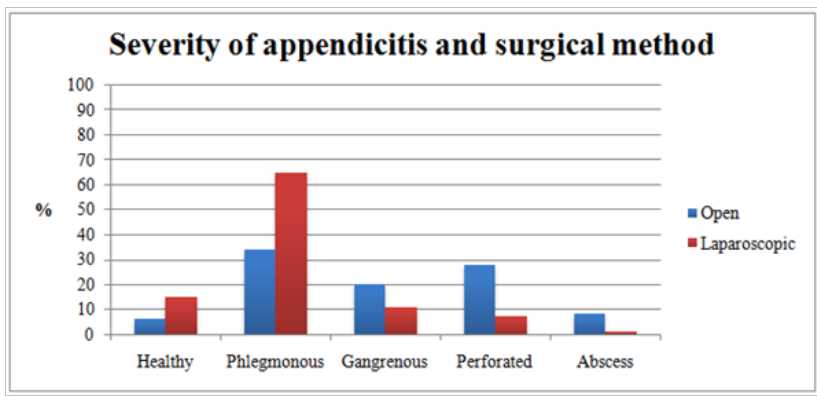

Figure 2 Appendicitis grade by surgical method in children receiving open or laparoscopic appendectomy.

\section{Discussion}

This retrospective study comparing the outcomes of OA and LA in children found no differences between the two methods regarding surgery time, complications, or postoperative pain treatment. The main finding was that patients with Phlegmonous appendicitis had a significantly shorter hospital stay when undergoing LA. Further, complicated appendicitis was more often treated with open surgery, while laparoscopic surgery was used more frequently for Phlegmonous appendicitis.

The hospital stay was shorter for children with Phlegmonous appendicitis who underwent LA. No significant differences were seen for gangrenous and perforated appendicitis and for appendiceal abscesses. Previous studies have shown that the hospital stay is decreased when LA is performed in all subgroups of both complicated and uncomplicated appendicitis. ${ }^{15,17}$ All inflammation groups treated with OA had a longer hospital stay, but the Phlegmonous appendicitis group was the only one with a significant difference. With more data and a larger study group, it is possible that the length of the hospital stay would also be significantly shorter in patients with complicated appendicitis undergoing LA.

The general consensus of earlier studies has been that surgery time is shorter with OA. ${ }^{14}$ There are also studies showing that the surgery time decreases with more training in the laparoscopic technique. ${ }^{15}$ However, our study did not show any difference in the surgery time between the two methods. This might be due to LA being the preferred method for treating appendicitis in our department. This implies that the surgeons have had much training, thereby reducing the surgery time for LA. Since open surgery is no longer the most common technique used to treat appendicitis, surgeons performing this operation might be less experienced, thereby leading to a longer duration of surgery. These factors could have contributed to the lack of difference between the groups.

Further, since OA is performed less frequently in our department and all surgeons must be educated in the technique, open surgery is more often performed by less experienced surgeons for educational purposes. This probably contributes to the longer surgery time in the OA group. Last, patients undergoing OA in the present study had more severely inflamed appendices. This might have prolonged the surgery time. This study showed a longer surgery time in both groups compared with previous studies. ${ }^{9}$ The present data were collected from a teaching hospital where education in surgery is provided on a daily basis, contributing to longer surgery times in both groups. Conversions from LA to OA were counted as OA, which was also a contributing factor to the longer surgery time in the OA group. Finally, both two- and three-trocar techniques were used for LA, which may have influenced the surgery time.

Postoperative pain treatment was not significantly different between the two groups in our study. This suggests that there is no difference in postoperative pain between the two techniques. In some earlier studies, less pain treatment was used in the laparoscopic group ${ }^{18}$ although other studies found no difference. ${ }^{14,19}$ In children, the total incision size is approximately the same for OA and LA. Therefore, the advantage of less pain after LA seen in adults may not be as prominent in children. The OA group and the LA group had a clear heterogeneity concerning inflammation grade. The OA group had a higher inflammation grade. Perforated and gangrenous appendices and appendiceal abscesses were more often treated with an open technique. In the LA group, Phlegmonous and healthy appendicitis dominated. Additionally, patients in the OA group had a significantly higher CRP level. The reason that complicated appendicitis is more often treated with an open technique could be explained by the preference of surgeons for an open technique in more severe cases and in sicker patients. Previous studies have shown that patients with a healthy appendix more frequently underwent LA. ${ }^{9}$ A laparoscopic method could be more frequently used in these patients because it enables diagnostic examination of the abdomen. ${ }^{9}$

Both techniques showed good results concerning postoperative complications. Postoperative abscess formation was higher in the OA group; this was the only postoperative complication difference between the groups. Previous studies have shown the opposite pattern, with more postoperative intra-abdominal abscesses occurring with LA. ${ }^{10}$ In the present study, children in the OA group had a significantly higher rate of complicated appendicitis, which surely explains this result; complicated appendicitis is more likely to lead to postoperative complications. ${ }^{15}$ Therefore, the higher incidence of intra-abdominal abscesses in the open group may be due to a selection bias and not an actual difference between the two techniques. For a more accurate result, further statistical analyses would have been necessary. These were not performed because of the low overall numbers of postoperative abscesses. No difference in wound infection rate was found between the two techniques, possibly because the total wound size is approximately the same for both. Previous studies have shown that wound infections are more common with open procedures. ${ }^{14}$ The reason the for lack of difference in wound infection rates in our study may be explained by the fact that the study group was small and the infection rate low.

The strengths of this study are that the preoperative, operative, and postoperative parameters were prospectively registered and thoroughly evaluated and that the follow-up was over three years. The number of patients is also sufficient to draw conclusions. The main weakness of the study is that the data were retrospectively gathered. Further, the LA group was not entirely homogeneous, including both two- and three-trocar procedures.

\section{Conclusion}

Because we found no disadvantages with LA and this method is associated with a significantly shorter hospital stay for many patients with Phlegmonous appendicitis, we would recommend LA in the future. The major advantage of this technique is the ability to inspect the abdominal cavity for other intra-abdominal diseases. 


\section{Acknowledgements}

To BioMed Proofreading LLC for edition of the manuscript.

\section{Conflict of interest}

The author declares no conflict of interest.

\section{References}

1. Sivit CJ, Siegel MJ, Applegate KE, et al. When appendicitis is suspected in children. Radiographics. 2001;21(1):247-262.

2. Addiss DG, Shaffer N, Fowler BS, et al. The epidemiology of appendicitis and appendectomy in the United States. Am J Epidemiol. 1990;132(5):910 925.

3. Samuel M. Pediatric appendicitis score. J Pediatr Surg. 2002;37(6):877881

4. Muehlstedt SG, Pham TQ, Schmeling DJ. The management of pediatric appendicitis: a survey of North American pediatric surgeons. J Pediatr Surg. 2004;39(6):875-987.

5. Newman K, Ponsky T, Kittle K, et al. Appendicitis 2000: variability in practice, outcomes, and resource utilization at thirty pediatric hospitals. $J$ Pediatr Surg. 2003;38(3):372-379.

6. McBurney C. IV. The incision made in the abdominal wall in cases of appendicitis, with a description of a new method of operating. Ann Surg. 1894;20(1):38-43.

7. Alkhoury F, Malvezzi L, Knight CG, et al. Routine same-day discharge after acute or interval appendectomy in children. Arch Surg. 2012;147(5):443446.

8. St Peter SD, Adibe OO, Juang D, et al. Single incision versus standard 3-port laparoscopic appendectomy: a prospective randomized trial. Ann Surg. 2011;254(4):586-590.

9. Esposito C, Borzi P, Valla JS, et al. Laparoscopic versus open appendectomy in children: A retrospective comparative study of 2,332 cases. World $J$ Surg. 2007;31(4):750-755.
10. Tang E, Ortega AE, Anthone GJ, et al. Intraabdominal abscesses following laparoscopic and open appendectomies. Surg Endosc. 1996;10(3):327328.

11. Ortega AE, Hunter JG, Peters JH, et al. A prospective, randomized comparison of laparoscopic appendectomy with open appendectomy. Laparoscopic appendectomy study group. Am J Surg. 1995;169(2):208212.

12. Chung RS, Rowland DY, Li P, et al. A meta-analysis of randomized controlled trials of laparoscopic versus conventional appendectomy. Am J Surg. 1999;177(3):250-256.

13. Azaro EM, Amaral PC, Ettinger JE, et al. Laparoscopic versus open appendicectomy: a comparative study. JSLS. 1999;3(4):279-283.

14. Sauerland S, Jaschinski T, Neugebauer EA. Laparoscopic versus open surgery for suspected appendicitis. Cochrane Database Syst Rev. 2010;(10):CD001546.

15. Ikeda $\mathrm{H}$, Ishimaru $\mathrm{Y}$, Takayasu $\mathrm{H}$, et al. Laparoscopic versus open appendectomy in children with uncomplicated and complicated appendicitis. J Pediatr Surg. 2004;39(11):1680-1685.

16. Andersson RE. Short-term complications and long-term morbidity of laparoscopic and open appendicectomy in a national cohort. Br J Surg. 2014;101(9):1135-1142.

17. Aziz O, Athanasiou T, Tekkis PP, et al. Laparoscopic versus open appendectomy in children: a meta-analysis. Ann Surg. 2006;243(1):17-27.

18. Lintula H, Kokki H, Vanamo K. Single-blind randomized clinical trial of laparoscopic versus open appendicectomy in children. Br J Surg. 2001;88(4):510-514.

19. Lejus C, Delile L, Plattner V, et al. Randomized, single-blinded trial of laparoscopic versus open appendectomy in children: effects on postoperative analgesia. Anesthesiology. 1996;84(4):801-806. 